\title{
( \\ El Derecho Humano al agua: una deuda del Estado con la población panameña
}

\author{
The Human Right to water: a \\ State debt with the panamanian \\ population
}

\section{O Direito Humano à água: uma dívida do Estado com a população panamenha}

\author{
Tomás Díaz Ríos
}

\begin{abstract}
Resumen
Panamá es un país favorecido en cuanto a recursos hídricos se refiere; sin embargo, se observa que el $10 \%$ de la población de la República carece de acceso al agua potable. Con base en los instrumentos internacionales y los compromisos con los Objetivos de Desarrollo del Milenio y los Objetivos de Desarrollo Sostenible de las Naciones Unidas, se fundamentará el "derecho humano al agua potable" en las nuevas reformas constitucionales desde el quehacer universitario. El objetivo principal de este estudio es permitir que los instrumentos jurídicos aseguren, a través de las garantías constitucionales a la población más vulnerable. Su aplicación será a través del derecho comparado. El método utilizado fue a través de la observación y el análisis de fuentes y datos secundarios. Se utilizaron las estadísticas proporcionadas por la Dirección de Planificación del Instituto de Acueductos y Alcantarillados Nacionales (IDAAN). Este artículo es parte de la sección de la investigación de la tesis doctoral "La huella hídrica; indicador para aplicar la circularidad del agua: modelo de gestión sostenible para Panamá”. Incorporar en la Constitución Política de la República de Panamá el texto sobre el derecho humano al agua pagará la mora que el Estado tiene con la población panameña, y los acuerdos suscritos internacionales. Los criterios analizados servirán para reflexionar sobre los temas de gestión y gobernanza del agua; y permitirá avances en materia de derechos humanos al agua, ayudará a impulsar el debido énfasis al reconocimiento del "derecho humano al agua para Panamá".
\end{abstract}

Recibido: 14-12-2020 - Aceptado: 13-5-2021

1 Docente-investigador y doctorando. Vicerrector de Maestrías, Postgrado, Investigación y Extensión de la Universidad Marítima Internacional de Panamá. Profesor de Geografía de la Universidad de Marítima Internacional de Panamá/Profesor de la Universidad de Panamá. Correo electrónico: tadiazr10@hotmail. com, tdiaz@umip.ac.pa. (D) https://orcid.org/0000-0003-4484-8284 
Palabras clave: Panamá, agua, derecho humano al agua, garantías constitucionales, quehacer universitario.

\begin{abstract}
Panama is a favored country in terms of water resources; however, it is observed that $10 \%$ of the population of the Republic lacks access to drinking water. Based on international instruments and commitments to the Millennium Development Goals and the Sustainable Development Goals of the United Nations, the "human right to drinking water" will be based on the new constitutional reforms derived from university work. The main objective of the present study is to allow legal instruments to reach, through constitutional guarantees, the most vulnerable population. Its application will be through comparative law. Employed methodology was by means of observation and analysis of secondary sources and data. The statistics provided by the Planning Directorate of the National Aqueducts and Sewers Institute (IDAAN) were used. This article is part of the research section of the doctoral thesis "The water footprint; an indicator to apply to the circularity of water: sustainable management model for Panama". Incorporation of the text on the human right to water in the Political Constitution of the Republic of Panama will pay for the delay that the State has had with the Panamanian population, and the international agreements signed. The criteria analyzed will serve to reflect on the issues of water management and governance; and will allow advances in the matter of human rights to water, it will help advance the emphasis on the recognition of the "human right to water for Panama".
\end{abstract}

Keywords: Panama; Water; Human right to water; Constitutional guarantees; University work.

\title{
Resumo
}

O Panamá é um país favorecido em termos de recursos hídricos; no entanto, observa-se que $10 \%$ da população da República não tem acesso a água potável. Com base em instrumentos internacionais e compromissos com os Objetivos de Desenvolvimento do Milênio e os Objetivos de Desenvolvimento Sustentável das Nações Unidas, o "direito humano à água potável” será baseado nas novas reformas constitucionais do trabalho universitário. O objetivo principal deste estudo é viabilizar instrumentos jurídicos que garantam, por meio de garantias constitucionais, a população mais vulnerável. Sua aplicação se dará por meio do direito comparado. O método utilizado foi por meio da observação e análise de fontes e dados secundários. Foram utilizadas as estatísticas fornecidas pela Diretoria de Planejamento do Instituto Nacional de Aquedutos e Esgotos (IDAAN). Este artigo faz parte da seção de pesquisa da tese de doutorado "A pegada hídrica; indicador para aplicar a circularidade da água: modelo de gestão sustentável para o Panamá ". Incorporar na Constituição Política da República do Panamá o texto sobre o direito humano à água pagará o atraso que o Estado tem com a população panamenha e os acordos internacionais firmados. Os critérios analisados servirão para refletir sobre as questões de gestão e governança da água; e permitirá avanços em matéria de direitos humanos à água, ajudará a promover a devida ênfase no reconhecimento do "direito humano à água para o Panamá.

Palavras-chave: Panamá; Água; Direito humano à água; Garantias constitucionais; Trabalho universitário. 


\section{Introducción}

La República de Panamá tiene una superficie total de 75990 km², y además, 2210 $\mathrm{km}^{2}$ de superficie de aguas territoriales. El Consejo Nacional del Agua CONAGUA (2016) confirma que el conjunto hídrico de Panamá cuenta alrededor de 500 ríos que drenan nuestro territorio, en 52 cuencas hidrográficas, que proporcionan, de esta manera, una disponibilidad de agua dulce de 119 mil millones de metros cúbicos per cápita. Panamá es un país con abundantes recursos hídricos, con una precipitación anual promedio de $3 \mathrm{mil} \mathrm{mm}$. Sin embargo, los recursos hídricos que dispone para los próximos años enfrentan los retos de permanencia de los fenómenos climáticos. Garcimartín et al (2020) sostienen que "el agua es, a su vez, un insumo fundamental en la economía panameña" (p. 2), importante para el dinamismo y crecimiento económico.

En definitiva, el agua es el recurso más importante para la vida; por lo tanto, Rocha da Silva (2018) lo considera como un bien natural, social-público y de uso común para la vida humana. "Actualmente, ese bien viene siendo comprometido por el factor económico" (p. 9); esencial para el desarrollo económico de los sectores geográficos de la producción; sobre todo, en nuestro país, para el funcionamiento del Canal de Panamá y la industria marítima auxiliar. Díaz (2020) señala que, en la actualidad, somos testigos de gran parte de la crisis y conflictos relacionados con los recursos hídricos, lo cual ha causado incertidumbre en las estructuras sociales en los últimos años. Es evidente que "el agua como recurso natural vaticina importantes retos que tenemos que enfrentar" (p. 88). Se busca reconocer el agua potable como un derecho humano desde una cuestión de dignidad y una titularidad legal.

Este artículo pretende señalar aspectos significativos relacionados con el derecho humano del agua y la deuda que mantiene el Estado con la población panameña. Observamos que Panamá posee un rico patrimonio hidrológico; y casi $10 \%$ de la población total de la República de Panamá no cuenta con el acceso al agua potable, según el último censo de 2010. Sánchez (2014) afirma que "los problemas del agua no son, como algunos sostienen, solo un problema de escasez, sino que aquéllos nacen de la desigualdad, la pobreza" (p. 554), y viven en marginación. En Panamá, las provincias más apartadas son las más vulnerables; principalmente las zonas indígenas que no gozan del acceso al agua potable y mejores condiciones de salubridad. Sin embargo, un porcentaje significativo de la población urbana localizada en la zona periurbana de la ciudad de Panamá no goza del acceso continuo al agua potable. Ibañez y Lazo (2018) explican que "los índices de marginación consideran como uno de sus elementos la falta de cobertura de agua potable" (p. 79); es decir, la presión demográfica que se vaticina en las próximas décadas, y el crecimiento poblacional estará acrecentando el problema del agua y la brecha en la sociedad. 
Este trabajo busca impulsar, desde el quehacer universitario, un capítulo constitucional en las nuevas reformas sobre el "derecho humano al acceso seguro al agua potable"; supone que la participación de la academia generará conocimiento y contribuirá al fortalecimiento de las instituciones y soluciones a la demanda de la sociedad. Orsolini (2015) comparte que esta propuesta permitirá "desarrollar un ordenamiento jurídico, en el marco de las garantías sugeridas para el derecho al agua" (p. 20), que conlleve al acceso del agua potable para mantener la vida y la salud de su población.

La República de Panamá tiene incluido, constitucionalmente, el recurso agua en el TÍTULO III sobre los DERECHOS Y DEBERES INDIVIDUALES Y SOCIALES y de manera específica en el Capítulo $6 .^{\circ}$ titulado SALUD, SEGURIDAD SOCIAL Y ASISTENCIA SOCIAL; en el Capítulo 7. ${ }^{\circ}$ del RÉGIMEN ECOLÓGICO en el Artículo 118; y en el Capítulo 8. en el RÉGIMEN AGRARIO en el Artículo 126. Este título constitucional presenta limitaciones en cuanto a que no está establecida la garantía de derecho humano al agua potable. Sin embargo, el agua no está incorporada en ninguno de los Capítulos de manera explícita; y actualmente se rige por el Decreto Ley n. ${ }^{\circ} 35$ de 22 de septiembre de 1966.

Para contraponer la crisis del agua, García y Carazo (2020) describen los esfuerzos que han permitido los "espacios internacionales para establecer y garantizar el agua como un derecho humano y bien común" (p. 14). Los países signatarios de los acuerdos y declaraciones internacionales sobre el derecho humano al acceso seguro al agua potable, han tenido que ser resarcidos por la obligación que tienen de garantizar el derecho a la supervivencia; aunque en el campo jurídico de la cuestión del agua posea un reconocimiento mínimo, su obligatoriedad es por justicia social.

Nuestra inquietud obedece a que nuestro país recientemente ha adquirido compromisos a través del cumplimiento de los Objetivos de Desarrollo del Milenio y los Objetivos de Desarrollo Sostenible. La consigna de gobierno "agua para todos", durante el periodo de gobierno 2014-2019 en Panamá, quedó como una promesa incumplida; y, desde la óptica del derecho humano al agua, las autoridades del Estado y el Órgano Legislativo dejaron una promesa incumplida. Observamos que a partir de estos objetivos se creó el Consejo Nacional del Agua (CONAGUA) y la Secretaría Técnica adscrita al Ministerio de Ambiente que estableció una hoja de ruta con el Plan Nacional de Seguridad Hídrica 2015-2050, "agua para todos"; pero al examinar el tema, no encontramos voluntad para cumplir. Señalamos que el problema real es que Panamá debe mejorar la gobernanza y gestión del agua.

Notamos, entre un grupo de la población, un descontento en la prestación del servicio del agua en Panamá. Al examinar los registros sobre el derecho humano 
al agua potable, empantanado, encontramos, por un lado, las normas que rigen la institucionalidad y las políticas públicas condicionantes de los recursos hídricos; por otro lado, las organizaciones sociales y los grupos ambientalistas reclamando la conservación y el acceso al agua; y desde la academia, solicitamos, como única salida, el orden jurídico de las garantías constitucionales del derecho humano al agua y la sostenibilidad de los recursos hídricos.

El diseño del estudio fue a través de los análisis de artículos y documentos relacionados con el derecho humano al agua y la observación de la cuestión del agua en Panamá. Se ha querido corroborar la información con los datos estadísticos obtenidos del Instituto de Acueducto y Alcantarillado Nacionales y del Instituto Nacional de Estadísticas y Censo de la Contraloría General de la República.

Los avances a partir de los derechos humanos y las resoluciones de Naciones Unidas están vinculados a los movimientos ecologistas y, ahora, desde el quehacer universitario hacemos el debido énfasis al reconocimiento del "derecho humano al agua para Panamá". Se busca que las garantías constitucionales protejan a los más vulnerables, con base en el derecho fundamental al agua en Panamá.

Por lo tanto, a través de las reflexiones sobre el derecho humano al agua y el estudio de esta garantía, el Estado fomentará una mejor gestión y gobernanza de los recursos hídricos en Panamá.

\section{Metodología}

Esta investigación es un estudio descriptivo correlacional, que consiste en observar la relación de la variable operacional: el derecho humano al agua; y la deuda del Estado con la población panameña. La técnica utilizada en este estudio fue la observación y el análisis de fuentes y datos secundarios. Este artículo presenta parte de la discusión planteada en la investigación de la tesis doctoral sobre "La huella hídrica; indicador para aplicar la circularidad del agua: Modelo de gestión sostenible para Panamá". Para corroborar la existencia de la falta de agua en la población panameña, se revisaron las estadísticas acerca del suministro de agua a nivel nacional, obtenidas del Instituto de Acueducto y Alcantarillado Nacionales y del Instituto Nacional de Estadísticas y Censo de la Contraloría General de la República; cifras que han sido comparadas con los acuerdos suscritos por Panamá a nivel internacional. Cabe resaltar que se empleó las estadísticas del último Censo de la República de Panamá 2010.

Los hallazgos obtenidos han sido interpretados y evaluados a partir de su justificación en los derechos universales al agua y la cuestión del agua en Panamá; y el 
rico patrimonio hidrológico conque cuenta la República de Panamá. Se utilizó un enfoque geográfico y de reclamaciones sociales. Se compara con experiencias de otros países para incorporar en las nuevas reformas constitucionales el derecho humano al agua, en un capítulo de nuestra constitución, que permitirá a través de instrumentos jurídicos asegurar garantías constitucionales para todos los ciudadanos del país. .

El derecho humano al agua potable en Panamá se fundamenta en la protección de las garantías constitucionales; Aguilar (2018) puntualiza que "reforzar el objetivo y la protección de este derecho a través del establecimiento de una legislación de carácter obligatorio" (p. 250), con el propósito de reflexionar sobre las obligaciones que adquiere el Estado es necesario para aplicar la norma constitucional del derecho humano al agua potable.

De esta manera, la cuestión del agua en Panamá será abordada desde la academia, con el propósito de contribuir con una discusión progresista al tema del agua y aportar a la deuda de miles de personas panameñas que carecen de acceso al agua potable. El objetivo es reducir el porcentaje de quienes, en el último censo de 2010, no tenían acceso continuo al agua potable, y poder garantizar una mejor calidad de vida para toda la población panameña. La "disponibilidad de agua implica aquella cantidad de litros por habitantes día que se destinan a la satisfacción de las necesidades de las personas" (Serrano et al, 2017); es decir, el Estado es el garante de los servicios públicos de agua potable, y el interés colectivo de toda la población.

\section{Conceptos universales sobre el derecho humano al agua}

Antes de presentar los conceptos universales sobre el derecho humano al agua, se expondrá, brevemente, en relieve, la importancia del agua desde la óptica divina y filosófica, y se examinará el derecho humano al agua en Panamá, a partir de las resoluciones y convenciones internacionales de las Naciones Unidas.

La existencia del agua adquiere un concepto importante desde el punto de vista teológico, hace referencia a la Deidad Suprema, al único Dios que menciona la Sagrada Palabra. La Santa Biblia (2003), en el Antiguo, en Génesis 1: 9 dice: "Y Dios dijo: Júntense las aguas que están debajo del cielo en un lugar, y aparezca el suelo seco. Y así sucedió" (p. 3). Todas las cosas fueron creadas por Dios. En el Nuevo Testamento el agua posee un fuerte significado y una dimensión sagrada también; Juan 4:14 nos habla: "Pero el que beba del agua que yo le daré, no tendrá sed jamás; sino que el agua que yo le daré será en él una fuente de agua, que 
brota para vida eterna" (p.887). Al comparar el agua espiritual, con el agua física constatamos que es un elemento natural para la vida.

El agua también adquiere su importancia desde el punto de vista filosófico; Guerrero (2009) ayuda a ilustrar su primicia del agua sobre los demás elementos:

Tales de Mileto, el filósofo griego del siglo VI a.C., afirmó que el agua era la sustancia original, de la cual todas las demás (tierra, aire y fuego) estaban formadas. Anaximandro, unos años más tarde, y otros filósofos después, concluyeron que más bien hay cierta proporción de fuego, aire, tierra y agua en el mundo, que cada uno lucha por extender su imperio y que se presenta la necesidad natural de restablecer el equilibrio. La consideración de Tales lleva mucha verdad en el sentido de que en todo hay agua; de hecho, Issac Newton, en el siglo VII, escribió su tratado De Natura Acidorum, en donde sostenía que todo cuerpo podía ser reducido a agua. (p. 14)

Lo cierto es que podemos resumir que el agua es el principio de todas las cosas y a partir de su origen se creó la vida, y dependemos de esta fuente natural para la supervivencia.

El acceso al agua potable es una de las medidas que universalmente se ha tomado en contra la batalla del hambre. Calvo-Brenes (2019) señala que "la insuficiencia de agua o la sequía prolongada puede provocar la muerte generalizada y el deterioro económico" (p. 105). Esto implica, sin duda alguna, el compromiso de los Estados de garantizar la vida de las personas y la supervivencia de la nación. Sin embargo, Mellado (2019) hace referencia a los orígenes del derecho humano al agua:

El derecho humano al agua ha sido deducido de las referencias de la Declaración de los derechos humanos de 10 de diciembre de 1948 y el Pacto Internacional de Derechos Económicos, Sociales y Culturales de 1966 a los derechos nucleares relativos a la protección de la salud, a la alimentación y a la vivienda. (p. 104) ${ }^{2}$

A partir de las declaraciones y pactos, nuestro país ha sido signatario también de otros acuerdos y convenios a nivel internacional. Observamos que estos instrumentos internacionales son reconocidos como un "derecho internacional"; por lo tanto, "si nos encontramos ante un auténtico derecho humano" (Mellado, 2019, p. 105), es este reconocimiento de carácter inclusivo para garantizar este derecho humano. Por lo tanto, "el agua es un recurso natural considerado un bien social público y de uso común" (Rocha da Silva, 2018, p. 59).

2 A pesar que el agua no se encuentra explícitamente incluido en la Declaración de los Derechos Humanos de 10 de diciembre de 1948 y el Pacto Internacional de Derechos Económicos, Sociales y Culturales de 1966, son los más importantes a principio del siglo XX de un Estado de bienestar social. 
En definitiva, la Asamblea General de las Naciones Unidas (2010) busca el goce pleno de la vida. Las Resolución A/Res/64/292 señala lo siguiente:

El informe de la Alta Comisionada de las Naciones Unidas para los Derechos Humanos sobre el alcance y contenido de las obligaciones pertinentes en materia de derechos humanos relacionado con el acceso equitativo al agua potable y el saneamiento que imponen los instrumentos internacionales de derechos humanos. (p. 2) ${ }^{3}$.

Los instrumentos internacionales que Panamá ha suscrito a través de convenciones internacionales sobre el derecho humano del agua origina esta discusión para establecer esta garantía como un derecho. Villanueva y Hidalgo (2016) confirman que "todos los Estados miembros de las Naciones Unidas han avalado el derecho humano al agua y saneamiento mediante el apoyo de uno o más documentos internacionales, como resoluciones y declaraciones" (p. 332); se entiende que el derecho humano al agua tiene su base jurídica en la obligación y garantía de los Estados en el reconocimiento de las convenciones internacionales. Además, su sustento en el concepto de la dignidad humana, definido por suficiente agua, accesible y asequible para uso personal y doméstico (Véase Figura 1). Observamos, que en el último Censo: 2010 XI de Población y Vivienda, lugares poblados de la República Volumen I-Tomo 3, el acceso al agua potable resulta más significativo en la Comarca Ngöbe Buglé con un total de 16110 viviendas particulares ocupadas sin agua potable; muy seguido de la provincia de Chiriquí con 13 699. La cobertura de acceso al agua en el país puede estimarse en casi un $94 \%$.

3 El derecho humano al agua y al saneamiento fue reconocido como un derecho humano por la Asamblea General de las Naciones Unidas el 28 de julio de 2010. 
Figura 1. Viviendas particulares ocupadas sin agua potable por provincias en la República de Panamá, Censo:2010

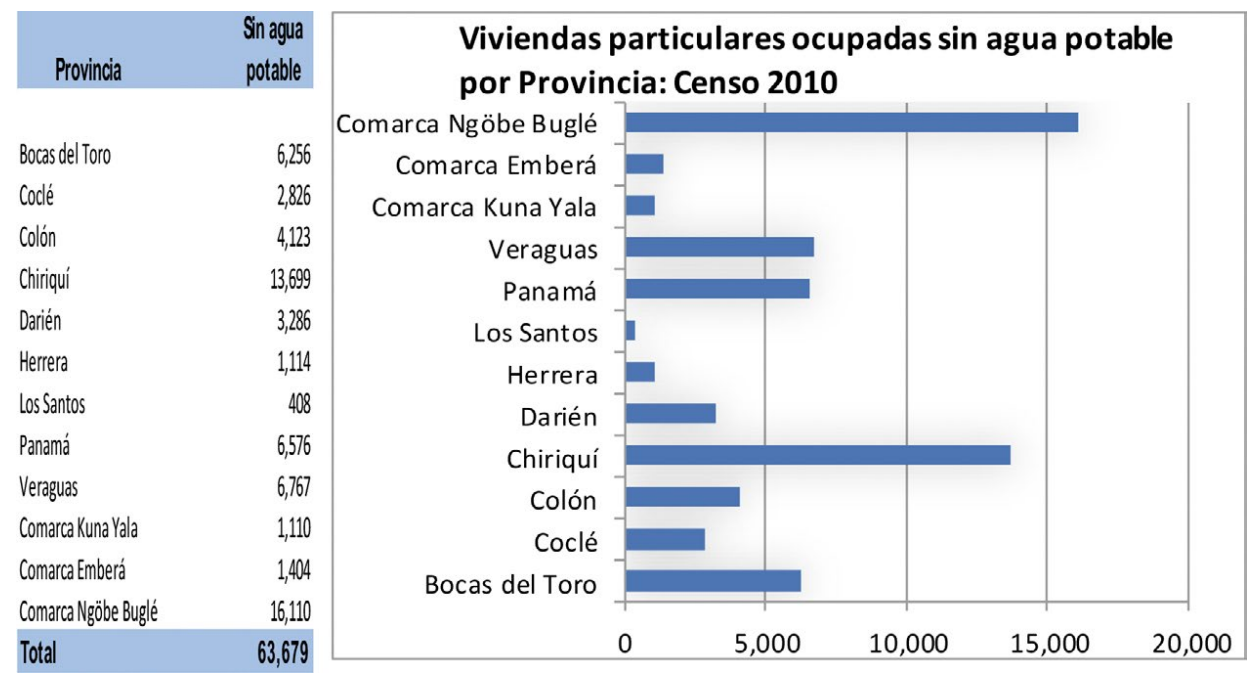

Nota: Instituto Nacional de Estadistica y Censo de la Contraloría General de la República de Panamá (2010).

De manera análoga, en la provincia de Panamá las estadísticas señalan que 6576 viviendas particulares ocupadas no cuentan con acceso al agua, situación que restringe las condiciones de igualdad, salud y desarrollo humano. Sin embargo, las desigualdades se reflejan en las áreas rurales y urbanas en el acceso, cantidad, continuidad y calidad de los servicios sobre todo en las comarcas indígenas; $\mathrm{y}$ en la provincia de Panamá en la periferia de la urbe capitalina. Consignar el derecho humano al agua en la Constitución panameña, será reconocer el legítimo derecho como ser humano a contar con el acceso y la cantidad suficiente para uso doméstico y personal; se estima en 50 a 100 litros por persona y día, situación que no se cumple y los medios de comunicaciones, testigos, señalan constante reclamaciones por parte de los pobladores afectados.

El derecho humano al agua es visto como una respuesta frente a las grandes tragedias humanas que acontecen en el planeta; por lo tanto, es considerado un "recurso natural indispensable para la vida humana: lo es para su supervivencia, la realización de otros derechos, la producción de alimentos y para el bienestar de las sociedades" (Villanueva y Hidalgo, 2016, p. 331). El derecho al agua es un principio que ha sido menoscabado por muchos años; ha causado enfermedades, desnutrición y ha desmejorado la calidad de vida de las personas. Villanueva y Hidalgo (2016) refieren, al respecto: "el contenido normativo designa los asuntos 
que los Estados deben tomar en cuenta en el reconocimiento de los derechos al agua y saneamiento" (p. 337). Sin embargo, este reconocimiento universal del derecho al agua hay que verlo por los avances que ha tenido la humanidad, lo cual debe estar incorporado en dichos derechos en nuestra legislación nacional. El Estado debe ser el principal impulsador de plasmar un marco jurídico de la Constitución Nacional sobre el acceso y disfrute del agua para todos.

En cuanto a la cuestión del agua en Panamá, encontramos más preguntas que respuestas a causa de la insuficiencia del acceso y suministro de este recurso, vital para la existencia. Se observa que en el último Censo del 2010 entre la población de la República de Panamá existen 63679 viviendas particulares ocupadas que están sin agua potable. El problema de escasez y la contaminación en las próximas décadas, amenaza la vida y salud de los panameños. Sánchez (2014) plantea que "aquellos que nacen de la desigualdad, la pobreza" (p. 554), y la usencia del agua y saneamiento, los hace más vulnerables a enfermedades. Se ha visto que una de las barreras más importantes para reducir el COVID-19 es el agua.

Se nota que existe un rico patrimonio hidrológico y que el desequilibrio existente es por la falta de acceso al agua potable; un problema de gobernanza y gestión. Martínez (2017) confirma:

Ante la existencia de agua en cantidad y calidad, cuando el círculo virtuoso no funciona, normalmente los fallos en la gobernanza tienden arrastrar el engranaje. Naciones Unidas (ONU) sostiene que los conflictos del agua son más que un problema de gobernanza que un problema de recursos. (p. 16-17)

\section{El debate del agua}

La cuestión del agua será abordada respondiendo las siguientes preguntas: si hay suficientes fuentes hídricas en Panamá para toda la población, ¿por qué no toda recibe el suministro de agua potable?, ¿qué modelo de gestión y gobernanza del agua contamos en nuestro país? En cuanto a las riquezas hídricas, el Consejo Nacional del Agua (CONAGUA) (2016) confirma el importante rol que juegan las precipitaciones en el territorio panameño:

La República de Panamá, cuenta con abundantes recursos hídricos y vasto patrimonio hidrológico. Es sustentado por una precipitación media anual de 2,924 litros de lluvia por metro cuadrado. Casi alrededor de 500 ríos drenan nuestro territorio,

4 Se observa que la insuficiencia del acceso al agua se debe principalmente a la gestión y gobernanza del agua; el equilibrio entre el Estado con políticas públicas que implican la trazabilidad en los sectores de la producción y el desarrollo humano. 
en 52 cuencas hidrográficas, proporcionando de esta manera una disponibilidad de agua de 119 mil millones de metros cúbicos de agua dulce per cápita disponible. (p. 11)

En Panamá, la disponibilidad total del agua dulce se estima en casi 119,5 mil millones de metros cúbicos, y solo se utiliza alrededor del 25,8 \%. El porcentaje de los recursos hídricos renovables totales asegura su total independencia hídrica, ya que todos tienen su origen en el país a diferencia de otros países como Paraguay y Argentina. La independencia hídrica de Panamá juega un papel significativo en nuestra economía y las operaciones del Canal.

Observamos que el problema del debate del agua no es la cantidad disponible del recurso hídrico, sino más bien, la voluntad estratégica de garantizar el acceso al agua y la sostenibilidad de las fuentes hídricas. La disponibilidad del agua es razón de conflictos a través de la historia; su acceso tiene profundas repercusiones en la educación, ecología, salud, política y otras áreas, y no podemos quedar exento del uso y dependencia de este recurso natural. Sánchez (2018) señala, en cuanto a la discusión del agua, plantea que esta marca "una relación entre el acceso a los servicios básicos de agua y saneamiento y la calidad de vida de los ciudadanos es intrínseca" (p. 49); cada vez más, aumenta el riesgo de escasez de agua, y es impredecible el peligro que se avecina sobre los recursos hídricos.

Por otro lado, el crecimiento poblacional está ocasionando un incremento en la demanda de los recursos hídricos; se intensifica el consumo de productos, de energía, y pone en riesgo la seguridad alimentaria. Esto pone en relieve el problema de "estrés hídrico", ocasionado por el alto consumo humano.

Hatch y Costa (2020) recuerdan, también, que los sectores ecologistas "exigen el reconocimiento del agua como un bien común y abogan por su protección social y conservación ambiental" (p.11); y buscan espacios de discusión en la Asamblea Nacional de Diputados de Panamá de fortalecer el derecho humano al agua.

Se observa que el agua sigue siendo un tema político e insuficiente del alcance social de todos. Como tema central de esta investigación se propone una propuesta a la nueva Constitución Nacional de Panamá de "reconocer implícitamente el derecho al acceso al agua potable por su relación con la dignidad humana y los derechos de incidencia colectiva" (Castro-Buitrago, et al., p. 198); modelo fundamental que proteja las garantías de toda la ciudadanía.

5 A pesar que la República de Panamá cuenta un sistema hídrico fructuoso y muy constantes generalmente, sin dependencia de otros países. 


\section{EI derecho humano al agua en Panamá}

Las políticas públicas adoptadas por el gobierno no encuentran una salida a la cuestión del agua en Panamá; en este sentido Recabarren (2016) afirma que "para garantizar el ejercicio de este derecho se requiere tanto la adopción de medidas políticas como jurídicas" (p. 325 ), en una gestión sustentable del agua. Panamá es uno de los países enlistados que no ha reconocido en su legislación, el derecho humano al agua en norma de rango constitucional. De este modo, García y Carazo (2020) coinciden que se necesita que el agua debe ser "gestionada a partir de los principios de la solidaridad, cooperación mutua, equidad, acceso colectivo y sostenible" (p. 16), por ende, Recabarren (2016) reafirma que Estado "es la garantía de este derecho se encuentra estrechamente vinculada con la protección" (p. 326), de los individuos, el medio ambiente y el crecimiento económico.

Por lo tanto, se observa que en nuestro país el cuestionable problema de los derechos humano al agua, se relaciona con dos ejes temáticos que entrelazan este tema: la gestión y gobernanza del agua. Se busca fortalecer la institucionalidad y mejorar las normativas relacionadas con los derechos humanos al agua; y desarrollar otros mecanismos adecuados de rendición de cuentas y evaluación para el seguimiento y progreso de las políticas públicas, que garanticen la sostenibilidad ambiental.

El reconocimiento del derecho humano al agua tiene como principios los instrumentos internacionales; en este sentido, Urquhart y Mezquita (2014) afirman:

Entender el agua como un bien fundamental exige ante todo un análisis en el marco teórico del Estado de Derecho, estructura jurídica-política abocada a la tarea de proteger y garantizar valores, bienes e intereses considerados relevantes (o supremos) por la sociedad. (p. 123)

El propósito es que al constituirse en un derecho humano es inalienable; todos tienen tienen el mismo derecho a gozar de estos derechos fundamentales. Delacámara et al., (2019) señalan que "enunciados por las Naciones Unidas, los Objetivos de Desarrollo Sostenibles incluyen, en el número 6, uno específico del agua: Garantizar la disponibilidad de agua y su gestión sostenible y el saneamiento para todos" (p.123). El derecho humano al agua se reconoció el 28 de julio de 2010, a través de la Resolución 64/292 en la Asamblea General de las Naciones Unidas, donde se constituyo que hay un derecho humano al agua y saneamiento.

\section{Marco jurídico de la gobernanza del agua}

La primera tarea es proponer e implementar los derechos humanos al agua y saneamiento como elemento fundamental en la gobernanza del agua en Panamá. La 
razón principal es que, a pesar de que contamos con suficientes fuentes hídricas, preocupa que hay sectores del país que no tienen acceso a este recurso; y, desde el quehacer universitario, acuñar el derecho humano al agua y saneamiento básico en la "Nueva Constitución de la República de Panamá".

CONAGUA, (2016) señala con respecto a las normas relacionadas al agua lo siguiente:
Algunas normas han quedado obsoletas con respecto a la evolución socioeconómica y urbana del país (por ejemplo, la Ley de Aguas de 1966, y el Código Sanitario de 1947), otras, cuyo mandato administrativo fue cambiado por otra norma (por ejemplo, el Decreto sobre Concesiones de agua de 1973 en el cual la competencia otorgada al MIDA fue traspasada a la ANAM con la Ley General de Ambiente). (p. 57)

Estas normativas dejan un vacío no solo con lo relacionado al uso de aguas subterráneas, sino también la consigna "Agua para Todos". Podemos entender que la gobernanza esta estrechamente vinculada a las normativas e instituciones, pero también con la capacidad de diseñar políticas públicas que sean socialmente aceptadas. Mussetta (2010) señala que "la gobernanza se refiere a la capacidad para gobernar en un sentido amplio -capacidad de acción estatal en la implementación de las políticas y en la consecución de las metas colectivas" (p. 74). En Panamá no existe la gobernanza que resuelva con eficacia y eficiencia los problemas del agua para todos los sectores de la población.

\section{Resultados}

Se observa que han pasado 59 años desde que el IDAAN se creó; responsable de administrar el agua potable en Panamá y todavía en pleno siglo XXI, el Estado mantiene una mora con el acceso al agua potable a la población panameña. Bahamonde (2019) señala que "pese a la importancia de garantizar el acceso de los seres humanos a la misma, hoy constituye un problema internacional de primer orden" (p. 16); producto de la incapacidad institucional, una mejor gobernanza y gestión de los recursos hídricos sostenibles. Se reconoce que el problema del agua preocupa a la sociedad panameña, pues es un tema de justicia social vital para la vida humana.

6 Las normativas nacionales de la República de Panamá, deben estar alinados con los Pactos y Declaraciones Internacionales, los Objetivos de Desarrollo del Milenio y los Objetivos de Desarrollo Sostenible, para ordenar jurídicamente un título constitucional sobre el derecho humano al agua. 
La precipitación anual es mayor al $2500 \mathrm{~mm}$ lo que hace un rico patrimonio hidrológico. Garcimartín et al. (2020) confirman que "su tasa de dependencia es cero, lo que significa que sus recursos hídricos tienen su origen en el mismo Panamá" (p. 2); asegura una total independencia respecto a los países limítrofes de Costa Rica y Colombia. El agua es parte del patrimonio hídrico de los países y representa un bien común, su acceso tiene que hacerse sin discriminación, y se debe disponer de un mínimo de agua suficiente para satisfacer las necesidades básicas y que la totalidad de sus habitantes tiene derecho a llevar una vida digna a pesar de su capacidad económica.

A pesar de que el derecho al agua es un derecho internacional, la República de Panamá no contempla una norma legal; García y Carazo (2020, p.16) amplían explicando que es necesario incluir un capítulo a rango "constitucional que contemple el acceso al agua potable y el saneamiento como un derecho humano". Se busca proteger el derecho de los individuos, consagrado en la Constitución, con el propósito de que las autoridades competentes cumplan lo dispuesto y la acción de cumplimiento se haga efectiva la aplicación de la norma.

La Constitución Política de la República de Panamá, en el TÍTULO III reconocido como DERECHOS Y DEBERES INDIVIDUALES Y SOCIALES. Se observa que de manera somera se menciona el agua, y no se encuentra debidamente identificado en los artículado de manera taxativa; como aparece en el Capítulo 6. Salud, Seguridad Social y Asistencia Social; el Capítulo 7. ${ }^{\circ}$ del RÉGIMEN ECOLÓGICO; y el Capítulo $8 .^{\circ}$ del RÉGIMEN AGRARIO; por ejemplo, en el Capítulo 6. ${ }^{\circ}$, La Asamblea Nacional de Diputados (2004) en nuestra constitución afirma en el Artículo 4:

Combatir las enfermedades transmisibles mediante el saneamiento ambiental, el desarrollo de la disponibilidad de agua potable y adoptar medidas de inmunización, profilaxis y tratamiento, proporcionadas colectiva o individualmente, a toda la población. (p. 26) ${ }^{7}$

Es fundamental evidenciar que el derecho humano al agua potable debe revisarse y su estudio debe ser sustentado con el instrumento del "derecho comparado" para la unificación jurídica; Ferrante (2016) define el derecho comparado "como una comparación entre dos o más sistemas jurídicos" (p. 605), amparado en el derecho

7 El agua es mencionada en la Constitución Política de la República de Panamá de manera insustancial; en el Capítulo 6. ${ }^{\circ}$, SALUD, SEGURIDAD SOCIAL Y ASISTENCIA SOCIAL en el Artículo 110, numeral 4; en el Capítulo 7. ${ }^{\circ}$ del RÉGIMEN ECOLÓGICO lo menciona en el en los Artículo 118 y120; en el Capítulo $8 .^{\circ}$ del RÉGIMEN AGRARIO en el Artículo 126, numeral 1. El agua debe presentarse en las reformas a la Constitución y otorgar un nuevo derecho ciudadano. 
extranjero de los países que han adoptado el derecho humano al agua potable. Se necesita, a través de la voluntad política, confirmar los compromisos firmados por la República de Panamá ante las Naciones Unidas y el cumplimiento de la agenda de los Objetivos de Desarrollo del Milenio y los Objetivos de Desarrollo Sostenibles, que responderá a las reivindicaciones de la ciudadanía. Los derechos fundamentales existen para que sean satisfechas sus necesidades básicas.

Se espera establecer, en la Constitución Política de Panamá, el Derecho Humano al Agua; Urquhart y Mezquita (2014) afirman que "constituye un derecho fundamental, necesita ser positivada como norma constitucional definidora de derechos acompañada con sus respectivas garantías" (p. 124), así se incorporará como un desafío de inclusión social acorde con la realidad social.

El proceso de iniciativa busca proponer la aprobación de la ley que garantice el acceso al agua potable; García y Carazo (2020) señalan que "el Estado parece mostrarse sordo a las demandas y necesidades de los sectores más vulnerables" (p.16). El propósito es incorporar en la Constitución de la República de Panamá un capítulo que asegure el acceso al agua potable y reduzca la desigualdad de los habitantes. El tratamiento ideal es a través del derecho comparado, con el propósito confrontar las semejanzas de los sistemas jurídicos vigentes en el mundo para aplicarlo en nuestro país. Ferrante (2016) aclara que "a la hora de interpretar y estudiar el texto extranjero, el comparatista debe entrar en el tejido jurídico" (p. 613), incorporando la doctrina y la jurisprudencia del derecho.

En cuanto a los temas de salud pública y la cuestión del agua, es preciso señalar que actualmente todo el planeta Tierra vive la angustia y devastación del mortal virus conocido popularmente como la nueva enfermedad de COVID-19; Conejo Luís et al. (2020) confirman que "la mortalidad en un área geográficamente amplia y que además causan graves consecuencias a nivel económico, social y político" (p. 2). Esta pandemia se ha propagado por todo el mundo, y Panamá no ha sido la excepción de este mortal virus. Esta nueva enfermedad ha cobrado la vida de centeneras de personas y en nuestro país ha superado la cifra de 5934 muertos. Sáenz-López et al. (2020) explican que "todo esto inició a finales del mes de diciembre de 2019, específicamente el día 31, en donde el Centro de Enfermedades de China reportó 27 casos de pacientes con neumonía de etiología incierta" (p. 1). La supervivencia contra la mortal enfermedad COVID-19 y primera barrera es el acceso al agua potable.

En definitiva, en el marco legal de Panamá, incorporar el derecho humano al agua en la Constitución Política de la República de Panamá permitirá ordenar las leyes y las políticas públicas que servirán a jueces y magistrados establecer las 
jurisprudencias "como garantía esencial mínima de prestación pública y justicia social" Mellado (2019, p. 108). El texto en la Constitución Política permitirá que el derecho humano al agua del ciudadano panameño sea un principio de solidaridad humana, de amparo y protección del servicio del Estado. Esta aspiración social será el nuevo instrumento jurídico que permitirá deliberar, como con otros derechos establecidos en la constitución, para lograr la equidad al acceso continuo al agua.

\section{Conclusiones}

La creciente demanda del acceso al agua en Panamá debe ser abordada en el marco de los derechos humanos al agua. Este establece obligaciones en relación con las declaraciones y resoluciones internacionales. Las personas privadas al acceso y abastecimiento del agua son muchas. Según el último Censo Nacional de Población de la República de Panamá del 2010, suman 63679 viviendas particulares ocupadas, que están sin agua potable. Aprobar el derecho humano al agua en la Constitución Nacional de la República de Panamá eliminará esta forma de discriminación y desigualdad sobre las personas.

Se han cumplido 10 años desde que el 28 de julio de 2010 las Naciones Unidas, a través de la Resolución 64/292, reconoció el derecho humano al agua y saneamiento, con el propósito de que los países adopten, en su constitución, este derecho; no solo para enfrentar los desafíos del cambio climático, sino también, las enfermedades como el COVID-19. Los Estados signatarios como Panamá tienen la obligación de respetar, proteger y cumplir para asegurar el agua potable como un derecho humano.

Con respecto a la cuestión del agua en Panamá, a causa de la incapacidad institucional que ha demostrado hasta hoy día, el gobierno de turno no muestra interés en impulsar la normativa que garantice el acceso equitativo del agua. Se observa que solo existe una hoja de ruta con el Plan Nacional de Seguridad Hídrica 2015-2050 como documento institucional; no se ha discutido en la Asamblea Nacional de Diputados de Panamá la aprobación para impulsar el derecho humano al agua potable.

El nuevo texto Constitucional permitirá garantizar el derecho humano al agua, al reconocer el amparo de los ciudadanos y del servicio del Estado. Las administraciones deben entender que el agua es un servicio público y debe prestarse con eficiencia y eficacia, sin recibir lucro de la población residencial.

Es significativo mencionar que el derecho al agua debe ser entendido al agua potable; y su existencia es condición para otros derechos como la alimentación. Además, el agua potable es un recurso natural importante para evitar el hambre y las enfermedades. 


\section{Referencias}

Calvo-Brenes, G. (2019). Nuevo índice para valorar la calidad de aguas superficiales en Costa Rica. Revista Tecnología en Marcha, 32(4), 104-115. https://doi.org/10.18845/ tm.v32i4.4796

Castro-Buitrago, E.; Vélez-Echeveri, J.; y Madrigal-Pérez, M. (2018), El derecho humano al agua en Colombia: Una mirada desde su reconocimiento jurídico en la gestión de cuencas hidrográficas. Revista de Gestión y Ambiente, 21. 195-206. https://doi. org/10.15446/ga.v21n2.73591

Conejo, L.; Chaverri-Chaves, P.; y León-González, S. (2020). Las familias y la pandemia de la COVID-19. Revista Electrónica Educare, 24(Suplemento Especial), 1-4. https:// doi.org/10.15359/ree.24-S.10

Constitución Política de la República de Panamá. (2004). TITULO III-DEBERES Y DERECHOS INDIVIDUALES Y SOCIALES, Capítulo $6^{\circ}, 7^{\circ}$ y $8^{\circ}, 15$ de noviembre de 2004. Texto Único del Reglamento Orgánico del Régimen Interno de la Asamblea Nacional de Diputados. Gaceta Oficial, N. ${ }^{\circ} 25176$. https://www.ilo.org/dyn/travail/ docs/2083/CONSTITUTION.pdf., p. 113

Delacámara, G.; Diez, J.; \& Lombardo, F. (2019). Seminario Permanente Agua, Territorio y Medio Ambiente, 13, 123-124. Universidad de Jaén, España https://doi.org/10.17561/ at.13.4134

Ferrante, Alfredo. (2016). Entre el derecho comparado y derecho extranjero. Una aproximación a la comparación jurídica. Revista Chilena de Derecho, 43(2), 601-618. http:// dx.doi.org/10.4067/S0718-34372016000200010

Hatch, G., \& Costa, W. (2020). Gestión del agua y relaciones de poder en América Latina. Revista Agua y Territorio, 15, 11-12. Universidad de Jaén, España. https://doi. org/10.17561/at.15.5492

Ibañez, O., y Lazo, J. (2018). El derecho humano al agua para excluidos en los municipios de Júarez y Guachochi, Chihuahua. Tecnología y Ciencias del Agua, 9(4), 75-109. https://doi.org/10.24850/j-tyca-2018-04-04

García, T.; \& Carazo, E. (2020). Ambigüedad institucional y normativa en la gestión y garantía del derecho humano al agua en Costa Rica: ¿Agua para quién? Revista Agua y Territorio, 15. 13-20. Universidad de Jaén, España. https://doi.org/10.17561/at.15.4646

Martínez, A. (2017). El agua y los retos del siglo XXI. Revista Aquae Papers, 7, 1-88. Aquae Fundación, Universidad Autónoma de Barcelona, España. 
Mellado, L. (2019, enero-abril). El derecho humano al agua como mínimo vital en Andalucía. Revista Andaluza de Administración Pública, 103, 101-143, Universidad de Almería. https://doi.org/10.46735/raap.n103.1075

Mussette P. (2009). Participación y gobernanza. El modelo de gobierno del agua en México. Revista Espacios Públicos, 12(25), 66-84. Universidad Autónoma del Estado de México.

Naciones Unidas. (28 de julio de 2010). Resolución aprobada por la Asamblea General A/RES/64/292 por lo cual se establece el derecho humano al agua y el saneamiento. naciones unidas y derecho al agua.pdf

Sáenz-López J., Rodríguez M. y García J. (2020). Predictores de mortalidad en pacientes con COVID-19. Archivos de Medicina, 16(26),1-3. 10.3823/1429

Sánchez, Álvaro. (2014). Injusticia ambiental y derecho humano del agua. Revista Thesis Juris, 3(2), 151-156. Sáo Pablo, Brasil. 10.5585/rtj.v3i2.186

Recabarren, O. (2016). El estándar del derecho de aguas desde la perspectiva del derecho internacional de los derechos humanos y del medio ambiente. Estudios Constitucionales, 14(2), 305-346.

Rocha, I., Ferreira L., y De Oliveira J. (2018). El agua como un bien social público: Los procedimientos de privatización frente al abastecimiento en Pau Dos Ferros-RN.

Revista GEOSUL, 33(68), 58-82. Florianópolis, Brasil. 10.5007/2177-5230.2018v33n68p58

Urquhart, S., \& Mezquita, D. (2014, enero-junio). El agua como un derecho fundamental y derecho al agua potable como un derecho humano fundamental: Una propuesta teórica de políticas públicas. Revista Jurídica, 11, 117-137. Manizales, Colombia.

174 Revista Latinoamericana de Derechos Humanos 